Table 2 presents the information exchange behaviours observed in the consultations with $95 \%$ or more of the providers. This overwhelming majority exchanged with SDM clients 16 specific items that covered the essentials of SDM counselling. Additionally, $90 \%$ of providers asked whether the client's husband would be able to abstain or use condoms on her fertile days. Conversely, $20 \%$ of providers posed barriers to access by refusing to supply the client with SDM tools unless her partner participated in the consultation. The requirement to study the menstrual cycle only occurred in one case.

Only six items from the pill checklist qualified for inclusion into Table 2. This is not because pill delivery is less complex but because providers did not address some important facts. For example, only $55 \%$ of providers asked the pill client if she had any heart problems, 20\% told her that she should start a new pill packet the day after finishing the previous one, $55 \%$ to take one active pill as soon as she remembered having forgotten to take one, $65 \%$ that she could experience headaches, and $20 \%$ to return to the clinic right away if her skin or eyes turn yellow. These and other provider behaviours of the checklist were essential considering the client characteristics.

\section{Discussion and conclusions}

The findings of this study confer international validity to three conclusions: SDM counselling is generally satisfactory, SDM training needs adjustment, and the rigor of providers' pill counselling remains below capacity.

Providers showed a satisfactory management of SDM cases in terms of the amount and nature of information exchanged with clients. The $70 \%$ of the provider behaviours expected in the consultations that were observed included the essential topics. This speaks well of the training system. However, the system needs adjustment to reduce the barrier to access that was posed by a minority of providers. The demand for the husband's presence probably responded to providers' concern regarding the SDM's effectiveness: pregnancy is likely if the partner does not co-operate in family planning. Yet the husband's presence at the consultation is not mandatory. If the client says that the husband will co-operate, she must be believed.

Providers exchanged a smaller amount of information with pill clients than with SDM clients even though most providers had delivered pills for years and all had recently participated in a 9-day contraceptive update. The consistency of the finding was evaluated through an unusual application of the $t$-test that required an effort of abstraction, since the SDM and pill checklists had different contents. This approach, however, is not new in the literature. ${ }^{12}$ Confirming that SDM counselling was more rigorous than pill counselling, the number of items that were observed in $95 \%$ or more of the consultations with SDM clients was more than double those observed with pill clients. Another methodological comment is that novelty factors do not seem to explain the SDM advantage, for the new method had been introduced 6 months earlier.
Hawthorne effects (i.e. exhibition of proficiency due to awareness of an evaluation) were unlikely since providers were blind to the simulated clients' presence in the clinics. Thus this study contributed evidence that the same providers that underperform in pill delivery can excel in the management of SDM cases (i.e. providers do not perform to their full capacity when they counsel clients on the pill). The solution to this problem will demand insightful analysis. To get providers to perform at their full capacity, SDM training centred on detailed job aids and set specific task goals (i.e. told providers exactly what to do with SDM clients). Job performance depends on the specificity of the worker's task goals ${ }^{13}$ and research has shown that the use of adequate job aids improves counselling. 6,7

\section{Acknowledgements}

Marcos Arévalo and Irit Sinai helped in instrument development, Theophile Nsengiyumva and Anastase Nzeyimana in data collection, and Claudia Velasquez in fieldwork co-ordination. INTRAHEALTH conducted the contraceptive update.

\section{Statements on funding and competing interests}

Funding. This study was funded under co-operative agreement HRN-A00-97-00011-00 between Georgetown University Institute for Reproductive Health and the United States Agency for International Development (USAID). The views expressed by the authors do not necessarily reflect those of USAID or Georgetown University. Competing interests. None identified.

References

1 Arévalo M, Sinai I, Jennings V. A fixed formula to define the fertile window of the menstrual cycle as the basis of a simple method of natural family planning. Contraception 1999; 60: 357-360.

2 Georgetown University Institute for Reproductive Health. The Standard Days Method: Reference Guide for Counseling Clients. Washington, DC: Georgetown University Institute for Reproductive Health, 2002.

3 Arévalo M, Jennings V, Sinai I. Efficacy of a new method of family planning: the Standard Days Method. Contraception 2002; 65: 333-338.

4 Rwanda National Census Service. 3rd General Census of Population and Housing: Report on the Preliminary Results. Kigali, Rwanda: Rwanda National Census Service, 2003.

5 León FR, Monge R, Zumarán A, García I, Ríos A. Length of counseling sessions and amount of relevant information exchanged: a study in Peruvian clinics. Int Fam Plann Perspect 2001; 27: 28-33,

6 León FR, Brambila C, de la Cruz M, García Colindres J, Morales C, Vásquez B. Providers' compliance with the balanced counseling strategy in Guatemala. Stud Fam Plann 2005; 36: 117-126.

7 León, FR, Ríos A, Zumarán A. Training $\times$ trainee interactions in a family planning intervention. Eval Rev 2005; 29: 576-590.

8 Luck J, Peabody JW. Using standardized patients to measure physicians' practice: validation study using audio recorders. $B M J$ 2002; 325: 679.

9 World Health Organization (WHO). Medical Eligibility Criteria for Contraceptive Use (3rd edn). Geneva, Switzerland: WHO, 2004.

10 World Health Organization (WHO). Selected Practice Recommendations for Contraceptive Use (2nd edn). Geneva, Switzerland: WHO, 2005

11 Kline RB. Beyond Significance Testing: Reforming Data Analysis Methods in Behavioral Research. Washington, DC: American Psychological Association, 2004.

12 Peabody JW, Luck J, Glassman P, Dresselhaus TR, Lee M. Comparison of vignettes, standardized patients, and chart abstraction. JAMA 2000; 283: 1715-1722.

13 Locke EA, Latham GP. A Theory of Goal Setting and Task Performance. Englewood Cliffs, NJ: Prentice-Hall, 1990

\title{
ERRATUM
}

\section{Complex inflammatory abdominal mass: a late complication of tubal clip sterilisation?,} Saha A, Clausen M, J Fam Plann Reprod Health Care 2006; 32(3): 186-187

The Journal wishes to apologise for any inconvenience or embarrassment caused to Mr Arabinda Saha that might have resulted from his name appearing in print as Arabinda Sahu on the front cover of the July 2006 issue of the Journal. 